\title{
The rejection of a diet which has been associated with a single administration of an histidine-free amino acid mixture
}

\author{
By P. C. SIMSON AND D. A. BOOTH* \\ School of Biological Sciences, University of Sussex, Brighton, Sussex $B N_{1} 9 Q Y$ \\ (Received 5 March $1973-$ Accepted 31 October 1973)
}

\begin{abstract}
I. A protein-free diet, to which an odour had been added, was offered to rats immediately after giving a gastric load of an histidine-free, but otherwise balanced, amino acid mixture. The same diet with a different odour was offered to the rats on another day, after administration of a control load of saline or a balanced amino acid mixture. After access to stock diet for $6 \mathrm{~h}$ of I d, the rats were offered two samples of protein-free diet, each with one of the two odours.

2. The rate of consumption of odorized protein-free diet was depressed $2-4 \mathrm{~h}$ after administration of the histidine-free load. In the later preference test, the dietary sample with odour which had been offered after the deficient load was rejected in favour of the sample with the odour which had been offered after the control load.

3. Rejection of the deficiency-paired odour in the final preference test did not occur when the histidine-free load had been given $2 \mathrm{~h}$ before the rats were first offered odorized diet. Also, there was in these instances no depression of rate of food consumption $2-4 \mathrm{~h}$ after loading. 'This indicated that aversive reactions to the odour were established by association of the odour with some effect of the histidine-free load which had occurred within $2 \mathrm{~h}$ of its administration, and that the early depression of intake and the much later rejection during choice were both expressions of these acquired reactions.

4. This rapid conditioning of selective rejection did not depend on previous prolonged protein deprivation or on the use of immature rats but did depend upon an intermittent supply of amino acids during $3 \mathrm{~d}$ before conditioning. Subcutaneous injection of deficient amino acid mixture did not establish rejection, suggesting that conditioning depended on rapid delivery of the deficient mixture into the circulation.

5. It is concluded that the critical biochemical events which lead to the rejection of diets that are imbalanced or deficient in essential amino acids occur soon after ingestion of the diet, and may have been effective in producing a conditioned aversion before any suppression of food intake appears. It is suggested that the depression of food consumption, which is the normal response to an imbalanced diet, is in this instance the result of conditioned response to sensory qualities of the diet rather than to the direct effect of biochemical stimuli.
\end{abstract}

Rejection of the diet appears to be the primary factor in the growth failure seen in rats offered diets which are disproportionate in amino acid composition (Harper, Benevenga \& Wohlheuter, I970). It has been suggested that the rejection of an amino-acid-imbalanced diet in favour of a balanced diet, or even a protein-free one, is a 'learned response' (e.g. Leung, Rogers \& Harper, I968). Kumta \& Harper (1962) found that there is a depression of intake of an histidine-imbalanced diet as early as a few hours after it is first offered to the protein-deprived young rat. Booth \& Simson (197I) and Simson \& Booth (1973) reported that the intake of an odorized proteinfree diet (PFD) is depressed from $3 \mathrm{~h}$ after a single intragastric load of an histidinefree, but otherwise balanced, amino acid mixture. The results of later preference tests indicated that the rats acquire an aversion to food with a specific odour when it is offered after administration of the histidine-free load (HFL) and that they prefer

* Present address: Department of Psychology, University of Birmingham, P.O. Box $36_{3}$, Birmingham Br 52 TT. 
the odorized food which has been paired with a water load. However, the rats prefer odorized food paired with an intragastric amino acid-balanced load to odorized food paired with a water load. Similar results are obtained when tastes rather than odours are added to the diet offered to rats after an amino acid load. It was concluded that postingestive effects of amino acid mixtures could act as unconditioned stimuli which establish conditioned responses to any distinctive orosensory stimulus associated with the diet. Zahler \& Harper (1972) reached the same conclusion, but did not attempt to control the conditioned stimuli.

The present work was undertaken to determine the time period after administration of an HFL at which the acquired aversion is induced, and to relate this to the earliest depression of intake and to gastrointestinal clearance of the load. We also investigated whether several days of protein deprivation and the use of rats weighing $100 \mathrm{~g}$ is necessary to establish the aversion.

\section{EXPERIMENTAL}

\section{Animals and diets}

Male albino rats of a Sprague-Dawley strain were supplied at 8o-100 g bodyweight by Oxford Laboratories Animal Colonies (Bicester, Oxfordshire).

The PFD was based on the maltodextrin MDo5 supplied by Manbré Sugars Ltd (London W6), which was a partly hydrolysed, palatable starch preparation. The diets contained $(\mathrm{g} / \mathrm{kg}): 5^{\circ}$ salt mixture (Rogers \& Harper, (1965), without sodium selenite); 0.25 vitamin mixture (Rogers \& Harper (1965), without the sucrose diluent but containing $0.02 \mathrm{~g} p$-aminobenzoic acid/kg diet); 50 maize oil (Mazola, Brown and Polson Ltd, Esher) and MDo5 to weight. The balanced amino acid mixture was $(\mathrm{g} / \mathrm{kg})$ : L-leucine I 19 ; L-isoleucine $55 ; \mathrm{L}$-valine 52 ; L-methionine 43 ; L-threonine 65; L-tryptophan 35; L-phenylalanine 68; L-lysine hydrochloride $\mathrm{I} 27$; L-arginine hydrochloride 78; L-monosodium glutamate 274 ; glycine 55 ; and L-histidine hydrochloride 29. Histidine hydrochloride was omitted in the histidine-free mixture. All salts, vitamins, amino acids and chemically defined odours were supplied by BDH Ltd (Poole, Dorset). Oils of lemongrass (citral) and eucalyptus were supplied by Griffin and George Ltd (Wembley, Middx) and were added to odorize the proteinfree diet at a level of $40 \mu \mathrm{l} / \mathrm{kg}$. Benzyl acetate or geraniol were added at $100 \mu 1 / \mathrm{kg}$.

\section{Experimental procedures}

On arrival the rats were placed in groups of four to six in $500 \mathrm{~mm} \times 250 \mathrm{~mm} \times$ $170 \mathrm{~mm}$ mesh cages in a room with a $12 \mathrm{~h} / 12 \mathrm{~h}$ lighting cycle and maintained at $20-22^{\circ}$. They had free access to water and a complete maintenance diet (autoclaved Small Animals Diet pellets; Spillers Ltd, London $\mathrm{EC}_{4}$ ). After $7 \mathrm{~d}$, the rats were re-housed individually in cages of the same size.

Unless otherwise stated, the procedure before conditioning was first to deprive the rats of food overnight and secondly to give them access $a d$ lib. for $54 \mathrm{~h}$ to PFD contained in glass jars $90 \mathrm{~mm}$ high with a $50 \mathrm{~mm}$ opening in the lid. A gastric load of $60 \mathrm{ml}$ casein hydrolysate solution $/ \mathrm{kg}$ body-weight $\left(\mathrm{BDH}\right.$ or Sigma, $\left.25^{\circ} \mathrm{g} / \mathrm{l}\right)$ was 
administered on the and day. Finally, rats were deprived of food for $18 \mathrm{~h}$ (overnight). Water was available at all times.

Conditioning. On 2 successive d, the rats were offered odorized PFD, in aluminium containers fixed within empty pet-food cans, for a fixed number of $h$ from Ir.oo hours. Intakes were weighed by difference every $2 \mathrm{~h}$. A pair of odours was used in each experiment, each rat having one odour on one day and the other on the next day. The odour pairs used in each experiment were benzyl acetate and geraniol (see Tables I and 3) and oils of lemongrass and eucalyptus (see Tables 2 and 4).

A gastric HFL, at a concentration of $\mathrm{I} 20 \mathrm{~g} / \mathrm{l}$, was administered on one conditioning day, and a control load on the other day. The control load was sodium chloride solution $(28 \mathrm{~g} / 1)$, approximately equal to the amino acid solution in osmotic pressure (see Tables I and 3), or the balanced amino acid mixture ( $120 \mathrm{~g} / \mathrm{l}$, see Tables 3 and 4 ). One group of rats in Table 4 received the amino acid loads as injections at several sites under the skin. The volumes loaded were ( $\mathrm{ml} / \mathrm{kg}$ body-weight): 50 (Table $\mathrm{I}$ ), 35 (Table 2), 65 (Table 3 ) or 20 (Table 4 ).

Groups of four rats received load and odour sequences and load-odour pairings which were counterbalanced within each group.

Preference testing. The rats were deprived of food overnight after they had been offered the second odour access. They were then given access for $6 \mathrm{~h}$ to the stock diet and deprived of food the following night. The following day they were given access for $3 \mathrm{~h}$ to two samples of PFD, each containing one of the odours used in the conditioning phase of the experiment. Intakes of both odorized samples were measured hourly.

Gastro-intestinal clearances. Young rats $\left(73^{-1} \mathrm{I} 2 \mathrm{~g}\right)$ were subjected to the pretreatment procedure, fasted overnight and given a gastric load of $5 \mathrm{ml}$ of the balanced or histidine-free amino acid solutions or saline $(28 \mathrm{~g} \mathrm{NaCl} / \mathrm{l})$. At $0.5, \mathrm{I}, 2$ and $4 \mathrm{~h}$ intervals, during which the rats were given access to water but not to food, the animals were anaesthetized with diethyl ether. When breathing had ceased, the gut was exposed and clamped immediately above and below the stomach and just anterior to the caecum. The stomach and small intestine were removed and the contents of each were washed out with a few $\mathrm{ml}$ of physiological saline. Two $\mathrm{ml} \mathrm{I} \mathrm{M}$-perchloric acid were added to the gut contents to precipitate protein, the suspension was neutralized with $2 \mathrm{M}-\mathrm{KOH}$ and the precipitate removed by centrifugation. The supernatant fluid was diluted to a known volume and total amino nitrogen was estimated by the colorimetric ninhydrin method of Matthews, Muir \& Baron (1964).

Statistical analysis. Depression of food intake on the day of administration of the HLF relative to intake on the day of the control load (conditioning phase), and food intakes during the choice between the two odorized diets (the preference test) were compared in each instance by simple difference and by a ratio score (the difference between the pair of intakes divided by the sum of the intakes). The ratio measure allows for variations in basal intake between rats. The sum of intakes, rather than the control intake, is used in the denominator because intake of the control odorized diet in the choice test is affected by the amount of experimental odorized diet consumed. In the event, the simple difference scores always gave the same pattern of 
results; therefore they are not reported. Ratio scores are given as percentages (ratio $\times$ 100). The statistical significance of the difference between zero and the group mean of the ratio scores was assessed by two-tailed correlated $t$ test (Sandler, 1955); $P$ $<0.1$ only is quoted.

\section{RESULTS}

Deficiency-induced rejection of food odour. Food intake ratios on the days of gastric loading with an HFL or saline, and in a subsequent preference test, are given in Table I. The negative ratios in the period $2-4 \mathrm{~h}$ after administration of the gastric loads, in rats offered odorized PFD for $4 \mathrm{~h}$ (group C) or $6 \mathrm{~h}$ (group D), reflect a depression of intake following the HFL relative to intake following the saline load. Also, in a preference test $2 \mathrm{~d}$ later, the odour paired with the HFL was rejected in favour of the saline-paired odour. Booth \& Simson (1971) found that, when water loads are given on the control day, rats reject an odour paired with an HFL, but acquire preference for an odour paired with a balanced amino acid mixture. This suggests that the rejection is a result of the omission of histidine from the mixture, not of any other properties of the HFL.

When the odorized diet was offered for a period of $2 \mathrm{~h}$ after administration of the gastric load, instead of for a period of $4 \mathrm{~h}$ or $6 \mathrm{~h}$, the rats (group A) showed no significant rejection of the deficiency-paired odour in the preference test. However, having had access to the PFD for $2 \mathrm{~h}$, this group was considerably more deprived on the 2nd day of gastric loading than the groups fed for 4 or $6 \mathrm{~h}$. This deprivation may have interfered with odour discrimination or with some physiological factor necessary to acquire an aversion, as the eight rats in the group which was given the HFL on the ist day showed a significant rejection of the deficiency-paired odour in the $3 \mathrm{~h}$ of the preference test $\left(-0.33, \mathrm{SE} 0 . \mathrm{I}_{5} ; P<0.10\right)$. The other half of the group, which received the HFL on the 2nd day, showed no preference for either of the odours $(-0.08, \mathrm{SE} 0.20)$. In fact, a feeding period of at least $4 \mathrm{~h}$ was needed before the earliest significant rejection of the diet was seen, and this provided the rats with sufficient experience of the food to establish a strong and long-lasting aversion.

Time of rejection-inducing effects. When the start of a $6 \mathrm{~h}$ period of access to odorized food was delayed until $2 \mathrm{~h}$ after gastric loading (group E), food intake was not significantly depressed at any period on the day of loading with the deficient amino acid mixture (Table I). Also, no rejection of deficiency-paired odour was apparent in the later preference test. This indicated that the rejection-inducing effects of the HFL were no longer present $2 \mathrm{~h}$ after administration of the load and the odour offered therefore did not become a conditioned stimulus. When a $2 \mathrm{~h}$ period of odour access began $2 \mathrm{~h}$ after gastric loading (group B), there was a significant attraction for the amino acid-associated odour in the later preference test (Table I). This could have been an effect of recovery from aversive effects of the load or an indication of some ultimately beneficial effect of the load.

The early depression of intake. There was no depression of food intake ratio for the period 2-4 $\mathrm{h}$ after administration of the HFL when the odorized diet was first offered $2 \mathrm{~h}$ after loading (groups $\mathrm{B}$ and $\mathrm{E}$ ). This could have resulted from the 
Vol. 3I

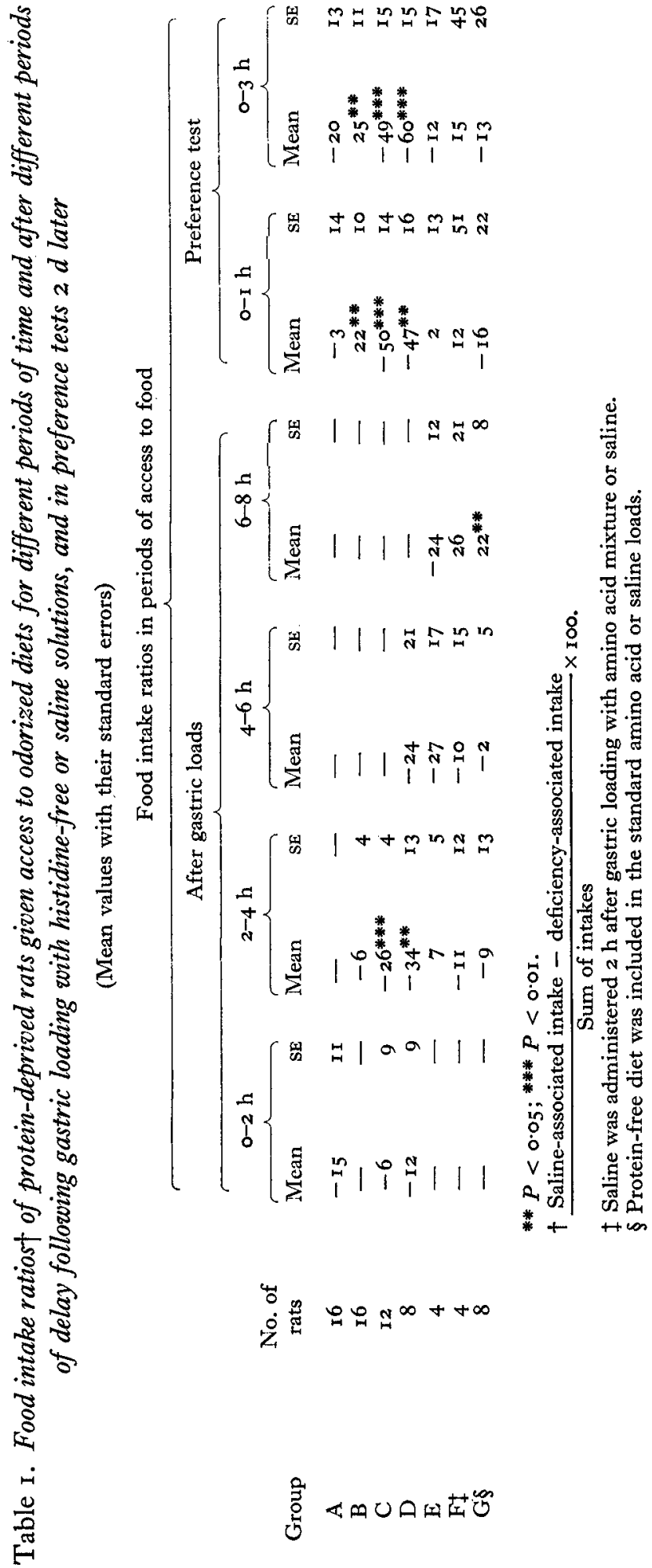


Table 2. Food intake ratios $\dagger$ of rats after feeding and gastric loading with casein hydrolysate preceding administration of balanced and histidine-free gastric loads

(Mean values with their standard errors)

Food intake ratios in periods of access to food

\begin{tabular}{|c|c|c|c|c|c|c|c|c|c|}
\hline \multirow{4}{*}{$\begin{array}{l}\text { Pretreatment with } \\
\text { casein }\end{array}$} & \multirow{4}{*}{$\begin{array}{l}\text { No. of } \\
\text { rats }\end{array}$} & \multirow{2}{*}{\multicolumn{6}{|c|}{ After gastric loads }} & & \\
\hline & & & & & & & & \multirow{2}{*}{\multicolumn{2}{|c|}{$\begin{array}{c}\text { Preference } \\
\text { test } \\
0-1 \mathrm{~h}\end{array}$}} \\
\hline & & \multicolumn{2}{|c|}{$o-2 h$} & \multicolumn{2}{|c|}{$2-4 \mathrm{~h}$} & \multicolumn{2}{|c|}{$4-6 h$} & & \\
\hline & & Mean & $\mathrm{SE}$ & Mean & se & Mean & $\mathrm{SE}$ & Mean & $\mathrm{SE}$ \\
\hline None & 8 & $I$ & 5 & $I_{5}^{* *}$ & 6 & $\mathbf{I}$ & 13 & 10 & 26 \\
\hline In drinking water & 8 & -6 & 7 & 34 & $2 \mathrm{I}$ & 6 & IO & $3^{8 * *}$ & $\mathbf{I}$ \\
\hline Gastric load & 8 & 4 & 9 & $28 *$ & 14 & I 8 & 14 & $37 * *$ & 13 \\
\hline
\end{tabular}

predominance of hunger over any appetite-depressant effect of the HFL; mean food intake in the period $2-4 \mathrm{~h}$ after the load on both loading days was $2.4 \mathrm{~g}$, while that for groups fed immediately after gastric loading was $\mathrm{I} \cdot 5 \mathrm{~g}$. Therefore, attempts were made to reduce this initial intake. Gastric loading with saline, immediately before rats (group F) were given access to odorized diet, did not reduce intake in the first $2 \mathrm{~h}$ period of delayed access $(2 \cdot 7 \mathrm{~g})$. However, this intake was reduced to the usual range ( $1.6 \mathrm{~g}$, group $\mathrm{G}$ ) when the gastric load of amino acids or saline was administered together with an aqueous suspension (300 $\mathrm{g} / \mathrm{l})$ of PFD, in an amount about the same as that caten, in the period $\mathrm{o}_{-2} \mathrm{~h}$ after gastric loading, by rats which were offered diet immediately after loading. The food intake ratio of this group in the period $2-4 \mathrm{~h}$ after loading did not reflect the depression of intake after the HFL which was seen in rats given access to odorized diet in the period $0-2 \mathrm{~h}$. This result indicated that the $0-2 \mathrm{~h}$ period of sensory experience of the odour was necessary to produce the depression in intake of food with that odour when it was offered in the period 2-4 h after loading, and also that the depression of intake was the result of an acquired reaction to the odour and not of a general loss of appetite. Also, food intake was not depressed in the period $4^{-6} \mathrm{~h}$ after gastric loading, and it was significantly elevated after the HFL in the period $6-8 \mathrm{~h}$ after gastric loading. Furthermore, the later preference test showed no significant rejection of the deficiencypaired odour. As there was no conditioned aversion to the odour and no depression in food intake on the day of gastric loading, it was likely that the depression of food intake at $2-4 \mathrm{~h}$ after loading in groups $\mathrm{C}$ and $\mathrm{D}$ was the earliest indication of an acquired aversion to the odour which had been presented during the $2 \mathrm{~h}$ when the HFL had had its aversion-inducing effects.

Dietary history and deficiency-induced rejection. The rats were restricted to $\mathrm{PFD}$ for a few days before administering the HFL (see Kumta \& Harper, I962). However, in our earliest experiments (Booth \& Simson, 1971), the rats were given access to hydrolysed casein solution once during protein deprivation, to adapt them to the taste and prepare them for voluntary intake of the deficient amino acid mixture. When this 


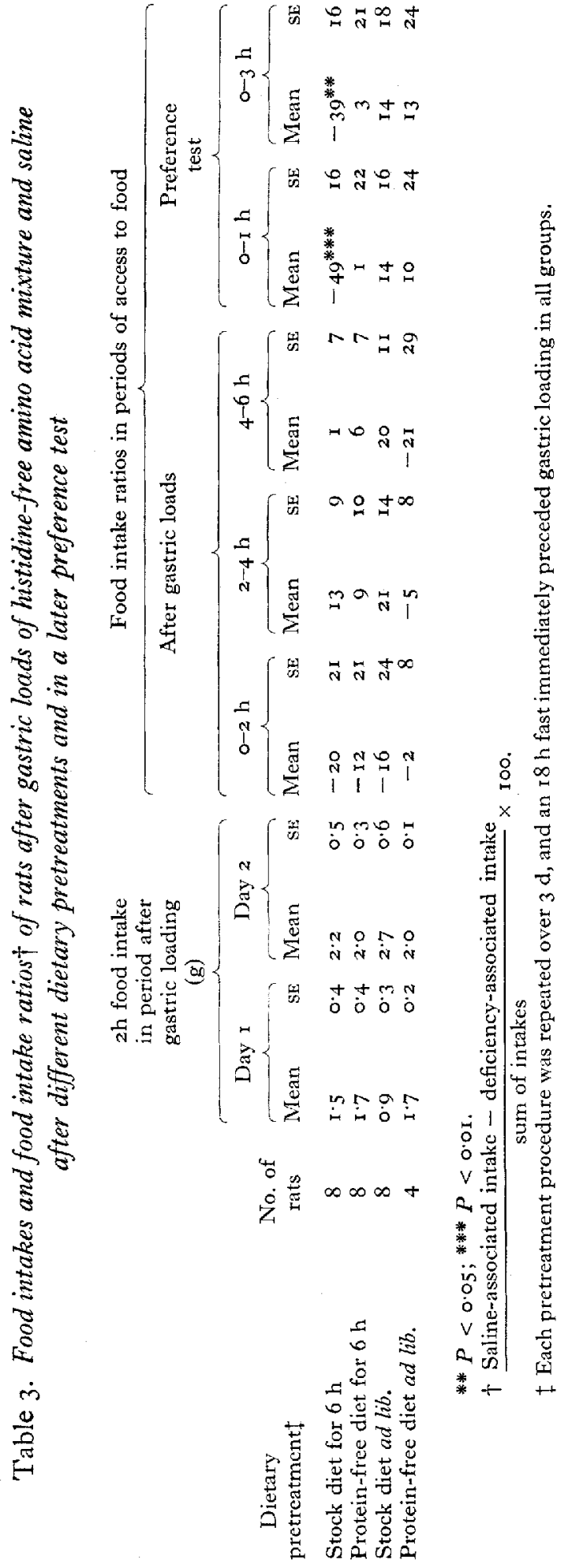


Table 4. Food intake ratiost of rats given gastric or subcutaneous loads of balanced or histidine-free amino acid mixtures

(Mean values with their standard errors of four rats/group)

Food intake ratios in periods of access to food administration

Intragastric Subcutaneous

\begin{tabular}{|c|c|c|c|c|c|c|c|c|c|}
\hline \multicolumn{10}{|c|}{ Food intake ratios in periods of access to food } \\
\hline \multicolumn{6}{|c|}{ After amino acid loads } & \multicolumn{4}{|c|}{ Preference test } \\
\hline \multicolumn{2}{|c|}{$0-2 \mathrm{~h}$} & \multicolumn{2}{|c|}{$2-4 h$} & \multicolumn{2}{|c|}{$4^{-6 h}$} & \multicolumn{2}{|c|}{$o-1 h$} & \multicolumn{2}{|c|}{$\mathrm{o}-3 \mathrm{~h}$} \\
\hline Mean & SE & Mean & SE & Mean & SE & Mean & $\mathrm{SE}$ & Mean & $\mathrm{SE}$ \\
\hline$-\mathbf{I 5}$ & I3 & $22 * * * *$ & 3 & 14 & 16 & $33^{*}$ & 16 & $3^{6 * *}$ & 12 \\
\hline 2 & I 5 & I I & 22 & $-\mathbf{I}$ & I6 & -22 & 26 & $-x_{3}$ & 27 \\
\hline
\end{tabular}

pretreatment with hydrolysate was omitted, no conditioned rejection developed (Table 2). When the rats were given casein hydrolysate to drink or when it was gastrically loaded during pretreatment, as in the rats of Table I, an odour paired with an HFL was rejected in favour of an odour paired with a balanced amino acid load. When casein hydrolysate was not given to the rats, there was only a slight depression of food intake on the day when they received the HFL, and no significant rejection of food of that odour was observed in the preference test $2 \mathrm{~d}$ later. Total food intake in the $\mathrm{I} h$ preference test was (g) $3^{\circ} \mathrm{O}$, SE 0.3 , with no appreciable variation among the three groups.

These results indicated that an extended period of complete deprivation of amino acids by itself is not a sufficient pretreatment in order to obtain deficiency-induced aversion. To elucidate this finding, comparisons were made between the effects of pairing gastric loads with odorized diets after the following pretreatments: giving PFD or stock diet in powder form ad lib. for $3 \mathrm{~d}$, or giving access to PFD or to stock diet for a $6 \mathrm{~h}$ period on each of 3 consecutive days. All dietary pretreatments ended with an overnight fast ( $18 \mathrm{~h}$ ), immediately followed by gastric loading and access to odorized diet. Only the group given access to stock diet for $6 \mathrm{~h}$ periods for $3 \mathrm{~d}$ showed acquired aversion to the odour paired with the HFL, with a preference for an odour paired with the saline load (Table 3 ). However, this group showed no significant depression of food intake on the day they received the HFL (Table 3). A lack of experience of eating the PFD may have produced the large differences between food intakes on day I and day 2 , and this difference masked the difference in intakes after the gastric loads. Intakes of PFD in the period $2-4 \mathrm{~h}$ after the gastric load were $(\mathrm{g}) 2 \cdot 1 \pm 0.2$ and $3.0 \pm 0.5$ on the Ist and 2 nd days respectively. Also the conditioning treatment was apparently more effective when the HFL had been given on the 2 nd day ( $3 \mathrm{~h}$ food intake ratio for preference test $-0.64, \mathrm{SE} 0.17$ ) than when it had been given on the Ist day $(-0.12$, SE $0.20 ; P<0.10)$ but was not as effective as the standard pretreatment procedure (Table $I$, group D). The novelty of the PFD given on the Ist day may have made the added odour less obvious to the rat 


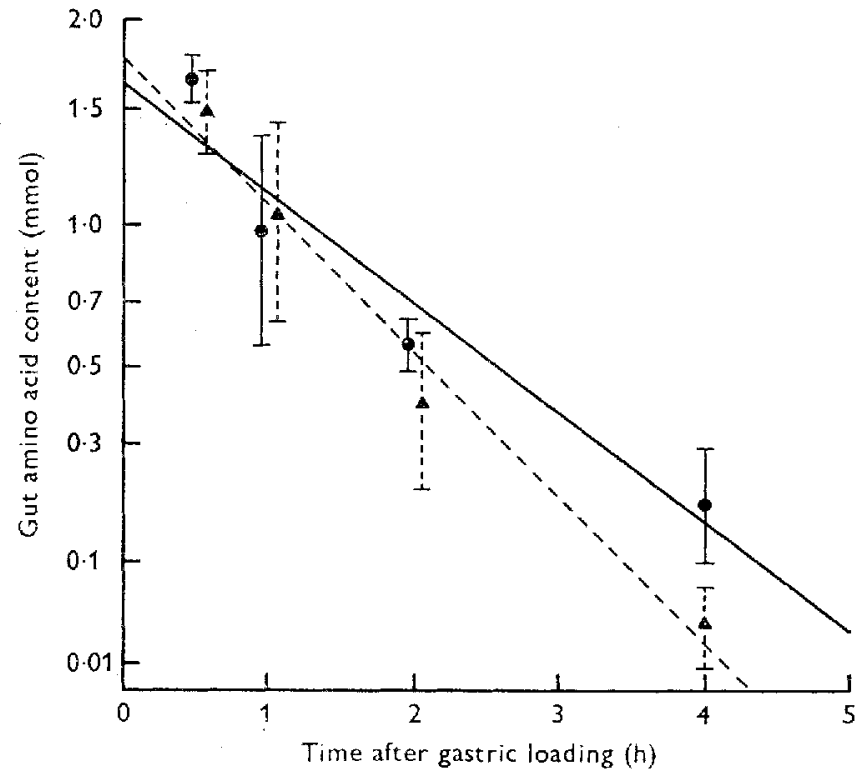

Fig. 1. Recovery of amino acids from the contents of the stomach and small intestine of rats after administration of a gastric load of a balanced - or an histidine-free $\mathbf{A}-\mathbf{\Delta}-\mathbf{\Delta}$ amino acid mixture $(3.35 \mathrm{mmol} / 5 \mathrm{ml})$. Mean values with their standard errors (vertical bars) for three rats in each instance.

on that day and therefore the aversion to the odour was less likely to be acquired than aversion to other sensory qualities of the diet.

The effect of age of rats and method of administration of amino acid mixture. Rats with initial body-weights in the range 224-304 $\mathrm{g}$ were given access to a solution of casein hydrolysate ( $100 \mathrm{~g} / \mathrm{l}$, giving $4 \mathrm{~g} / \mathrm{kg}$ body-weight) and the PFD for $48 \mathrm{~h}$ and were then fasted for $20 \mathrm{~h}$. A group of four rats which had received a gastric HFL later rejected the odour presented from the time of the load, in favour of the odour which had been paired with an intragastric load of a balanced amino acid mixture (Table 4). There was, however, no significant conditioned aversion in rats subcutaneously injected with the same pair of loads. Furthermore, these differences in response in the delayed preference test were paralleled in the intake responses on the days when rats received the amino acid loads: food intake was significantly depressed in the period $2-4 \mathrm{~h}$ after gastric administration of the HFL, but was not depressed after subcutaneous administration.

Absorption of amino acid loads. In Fig. I the solute concentration is plotted on a square-root scale, on the assumption that intestinal osmotic control of gastric cvacuation controls absorption and so the function is similar to that found with carbohydrate loads (Hopkins, I 966). The intragastric load of either the balanced or histidine-free amino acid mixture ( $8 \mathrm{~g} / \mathrm{kg}$ body-weight) passed out of the stomach and intestine very rapidly after administration; half or more disappeared from the gut in the first 30 min after gastric loading. Most of the load had been absorbed within $2 \mathrm{~h}$ in both instances. At all times after a saline load, the amounts of amino- $N$ detected in the gut were less than $0.075 \mathrm{mmol}$. 
DISCUSSION

Dietary history and rejection of the diet related to amino acid deficiency. The results indicate that previous intermittent administration of amino acid loads to rats facilitates the rejection of a diet which has been offered in association with a disproportionate mixture of amino acids. Complete exclusion of protein and amino acids from the diet or $a d l i b$. feeding on stock diet for $2 \mathrm{~d}$ or more, followed by an overnight fast and administration of an amino acid-deficient mixture, prevented the induced rejection. The rejection was observed when casein hydrolysate was administered during the initial period of feeding on PFD or when the rats had limited daily access to stock diet (quoted as 2 rog protein $/ \mathrm{kg}$ diet by Spillers Ltd). Previous access to an imbalanced diet was not necessary, contrary to the suggestion by Nasset, Ridley \& Schenk (1967). Peng, Tews \& Harper (1972) have recently found a rapid and substantial reduction in intakes of histidine- or threonine-imbalanced diets offered $a d$ lib. to rats given access to a diet containing methionine, threonine and $65 \mathrm{~g}$ casein $/ \mathrm{kg}$ diet for repeated periods of $\mathrm{I} 2 \mathrm{~h}$.

The mechanism by which dietary pretreatments permit the acquisition of dietary aversions has not been established. Food deprivation before access to the diet, familiarity with diets similar to the deficient diet, and experience of intermittent feeding may all facilitate rapid discrimination of the distinctive orosensory and postingestive qualities of the diet which will eventually be rejected. Protein-rich gut secretions which mask an amino acid imbalance (Nasset, 1964) may also be reduced in quantity. The force-feeding with casein hydrolysate (Sahib \& Krishna Murti, 1969; Lee, Tews, Morris \& Harper, 1972) or even with an histidine-free amino acid mixture (Myasoedova, I966) is followed by at least twofold increases in the activities of hepatic histidase and other enzymes of histidine catabolism. The apparent half-life of the induced histidase is $2 \cdot 1 \mathrm{~d}$ (Lee et al. 1972). Therefore, rats pretreated intermittently with amino acid-containing nutrients would be capable of degrading endogenous histidine rapidly, increasing the relative shortage of this amino acid during overnight fasting before the HFL. Maintenance of a capacity for rapid protein synthesis might also contribute to the shortage. The omission of histidine from the amino acid intake of the rat may facilitate rapid development of dietary rejection more than the omission of other amino acids. Rejection of the diet was observed in our experiments in adult rats which had undergone the appropriate dietary pretreatment generally associated with rejection, as well as in immature rats, to which histidine supply may be particularly critical.

Acquisition of flavour-controlled rejection of disproportionate diets. It is possible that the rejection of an amino-acid-imbalanced diet is the result of a conditioned aversion to sensory qualities of the diet which is acquired by their association with postingestional effects of the amino acids. Odour cues were deliberately provided in this study. Taste and texture cues were obviously available to the rat in some reported experiments on the rejection of imbalanced diets in favour of a PFD (Leung \& Rogers, 1971 ; Leung, Larson \& Rogers, 1972). These cues were almost certainly eliminated in the rejection of imbalanced diet in favour of a corrected diet (Leung et al. 1968); 
however, the full rejection took longer to develop in that experiment. When neither these oral cues nor spatial cues are available as a basis for the rat's preference, adventitious olfactory cues are likely to be used (Le Magnen, 1959), including odours placed on or near the food by the rat itself. A persistent, completely selective, rejection of a diet cannot be caused by deleterious or satiating effects occurring during continued ingestion of the diet, and must be based on some sensory discrimination. When the rejection is incomplete, it is likely to result from a reaction to a sensory cue in anticipation of postingestional effects, because these could not become strong in a brief period of feeding.

Whether the acquired aversion is peculiar to force-fed HFL has not been established. The biochemical and behavioural effects of the administration of a large amount of an histidine-free, but otherwise balanced, amino acid mixture may differ quantitatively from the effects of smaller amounts of mixtures from which another essential amino acid has been omitted, or which are imbalanced in amino acid composition but are not deficient. It has been suggested that the biochemical effects also differ qualitatively (Harper et al. 1970 ), but this remains to be established for effects occurring shortly after a single gastric load or a brief period of feeding, which our results indicate to be the effects most relevant to rejection of the diet.

The rejection-inducing effect of the HFL was chemically specific. This load is a balanced mixture of amino acids with its proportionately small amount of histidine (29 $\mathrm{g} / \mathrm{kg}$ of mixture) omitted. The control load in two of these experiments (Tables 2 $\& 4$ ) and in some reported work (Booth \& Simson, 1971) was the balanced mixture at the same dose; in these instances the rejection of the odour associated with the HFL was in favour of the odour associated with this control load differing only in histidine content. The appearance of the rejection when hypertonic saline was used as the control load in the other experiments (Tables I \& 3 ) indicates that an osmotic effect was not involved. As the balanced amino acid load induces a preference relative to this saline load (Simson \& Booth, 1973), these results are also consistent with a chemically specific basis for the conditioned rejection induced by the HFL.

Time of rejection-inducing postingestive effects. Under the conditions of these experiments, rejection only occurred if the rat smelt the diet within $2 \mathrm{~h}$ of receiving the HFL, when most of the load was absorbed. It is generally accepted that rejection of imbalanced diets results from the postabsorptive action of the amino acids; intravenous administration of the deficient amino acid eliminates the depression of food intake (Leung \& Rogers, I969; Peng \& Harper, I 969), possibly by substituting an acquired appetite for the acquired aversion (Booth \& Simson, 1971; Simson \& Booth, 1973). The crucial effects may occur during the period of most rapid absorption, within half an hour of taking a meal or receiving a gastric load. A subcutaneously injected solute diffuses only slowly into the circulation (Lukas, Brindle \& Greengard, 1971) and was found to be ineffective at a dose which was effective intragastrically. Amino acids administered to the stomach are transported actively in the intestine and half the load was observed to be absorbed within $30 \mathrm{~min}$. The plasma amino acid pattern resulting from the rapid absorption may then act on the brain (Leung \& Rogers, 1969) to change the reactions to recently experienced food cues, an associative 
learning phenomenon which can affect feeding behaviour by the $3^{\text {rd hour after }}$ gastric loading. In studies of the voluntary intake of imbalanced diets, the earliest signs of a depression in food intake are observed between 2 and $6 \mathrm{~h}$ after giving access to the diet (Kumta \& Harper, 1962; Sanahuja \& Rio, 1967; Peng et al. 1972), in which substantial intakes in the first $30-60$ min of access to food may have initiated the postabsorptive conditioning of dietary aversion. Once acquired, the aversion persists for many weeks after a single association (Booth \& Simson, 1971). It may be reversed by enforcing a conflicting associative experience. Rejection by the rat of a threonine-imbalanced diet in favour of PFD persists after intake of sufficient threonine to correct the imbalance, until the animals are forced to take substantial amounts of the corrected diet by removal of the PFD (Leung et al. r968).

'These results indicate that the depression of the intake of an imbalanced or deficient diet will not be explained by the biochemistry of blood and tissues some hours, or even days, after the diet has been offered to the rat. The rat may be rejecting the diet because of an aversion to the sensory qualities of the diet which was established by biochemical events within an hour of its first meal.

This work was supported by a grant from the Medical Research Council.

\section{REFEREN CES}

Booth, D. A. \& Simson, P. C. (1971). Q. Jl exp, Psychol. 23, 135.

Harper, A. E., Benevenga, N. J. \& Wohlheuter, R. M. (1970). Physiol. Rev. 51, 428.

Hopkins, A. (1 966). F. Physiol, Lond. 182, I44.

Kumta, U. S. \& Harper, A. E. (1962). Proc. Soc. exp. Biol. Med. 110, 5 I 2.

Lee, S. H., Tews, J. K., Morris, M. L. \& Harper, A. E. (1972). F. Nutr. 102, 3 I9.

Le Magnen, J. (1959). 7. Physiol., Paris 51, 987.

Leung, P. M.-B., Larson, D. M. \& Rogers, Q. R. (1972). Physiol. Behav. 9, 553.

Leung, P. M.-B. \& Rogers, Q. R. (1969). Life Sci. 8, r.

Leung, P. M.-B. \& Rogers, Q. R. (I97I). Am. F. Physiol. 221, 929.

Leung, P. M.-B., Rogers, Q. R. \& Harper, A. E. ( 968 ). 7. Nutr. 95, 483 .

Lukas, G., Brindle, S. D. \& Greengard, P. (1971). F. Pharmac. exp. Ther. 178, 562.

Matthews, D. M., Muir, G. G. \& Baron, D. N. (1964). F. clin. Path. 17, I 50.

Myasocdova, K. N. (1966). Biokhimiya 31, 182.

Nasset, E. S. (1964). In The Gastrointestinal Tract in Protein Metabolism, p. 83 [H. N. Munro, editor].

Oxford: Blackwell.

Nasset, E. S., Ridley, P. T. \& Schenk, E. A. (1967). Am. F. Physiol. 213, 645.

Peng, Y. \& Harper, A. E. (1969). Am. F. Physiol. 217, I44I.

Peng, Y., Tews, J. K. \& Harper, A. E. (1972). Am. F. Physiol. 222, 314.

Rogers, Q. R. \& Harper, A. E. (1965). \%. Nutr. 87, 267.

Sahib, M. K. \& Krishna Murti, C. R. (1969), f. biol. Chem. 244, 473 .

Sanahuja, J. C. \& Rio, M. E. (I967). F. Nutr. 91, 407.

Sandler, J. (1955). Br. F. Psychol. 46, 225.

Simson, P. C. \& Booth, D. A. (r973). Q. Il exp. Psychol. 25, 354.

Zabler, L. P. \& Harper, A. E. (I972). J. comp. physiol. Psychol. 81, I 55. 